\title{
HANNA ARENDT Y LA CRÍTICA DE LA FACULTAD DE JUZGAR
}

\section{Diana María López UNL-UCSF}

\begin{abstract}
"El lapso de vida del hombre en su camino hacia la muerte llevaría inevitablemente a todo lo humano a la ruina y destrucción si no fuera por la facultad de interrumpirlo y comenzar de nuevo, facultad que es inherente a la acción a la manera de recordatorio siempre presente de que los hombres, aunque han de morir, no han nacido para eso sino para comenzar".
\end{abstract}

H.ARENDT: La condición humana.

\section{a. Presentación.}

La obra de Hanna Arendt, -desde La condición humana (1958) hasta The Life of the Mind (1978) ${ }^{1}$ - es difícil de clasificar dentro de los parámetros políticos o filosóficos tradicionales. En un contexto en el que despliega una paradójica voluntad de responsabilizar a la filosofía por el destino de la modernidad y al mismo tiempo hallar en ella la posibilidad de salvarla, se interroga sobre las repercusiones que los alcances de la "filosofía primera" tienen sobre la comprensión de la esfera práctica y las razones que la han

\footnotetext{
${ }^{1}$ Arendt, H., La condición humana, Barcelona, Paidós, 1993 (En adelante CH) y The Life of the mind, New York, 1978. (Trad. cast.: La vida del espiritu, Madrid, Centro de Estudios Constitucionales, 1984. (En adelante LM) Para un acercamiento biográfico a la obra de Hanna Arendt, remito al texto de Elisabeth Young-Bruehl, Hanna Arendt. For Love of the World, New Haven, Yale University Press, 1982 (trad.esp.: Hanna Arendt, Valencia, Edicions Alfons el Magnànim-IVEL, 1993). Por otra parte, para una acertada "localización" de la trayectoria filosófica de Arendt remito al volumen colectivo En torno a Hanna Arendt, Madrid, Centro de Estudios Constitucionales, 1994.
} 
llevado a comprometer una auténtica consideración de los problemas humanos.

Kant tiene un rol fundamental en la obra de disolución de esta tendencia de fondo de la metafísica que la autora asume de modo particularmente eficaz en sus últimas obras. Baste aquí sólo destacar que -a través de una lectura selectiva y proyectiva de los textos kantianos ${ }^{2}$ - la Arendt elimina todos aquellos indicios que a su parecer, testimonian la familiaridad "fundacionalista" y "universalista" del filósofo alemán con la tradición filosófica occidental. Se podría decir que nos presenta, no un Kant prehegeliano, todavía ajeno a la "potencia de la negatividad", sino un Kant post-hegeliano, o directamente, post-metafísico que, casi como si hubiese pasado a través de la filosofía de la existencia, se vuelve a reflexionar sobre la "finitud" de nuestro ser y sobre la indivisible pertenencia de hombre y mundo.

La reflexión más sistemática de Arendt en lo que hace a su propio pensamiento político se encuentra en The Human Condition. Su concepción de vita activa cubre todos los modos de actividad humana, incluída la actividad política. Esta última, lejos de quedar circunscripta a las tareas de legislación y de gobierno - conforme se desprende de la lectura de un texto clásico como la República de Platón- tiene que ver con la articulación de la teoría y de la praxis de tal modo que el "mundo de las apariencias" no se vea subordinado a "fines superiores" desde los cuales adquiere sentido. La acción representa así, el momento culminante de la vita activa por su propia capacidad para un nuevo comienzo espontáneo e indeterminado por causas anteriores, pero además, la dimensión huma-

\footnotetext{
2 Los ensayos de Lectures on Kant, publicación póstuma de Beiner como Lectures On Kant's Political Philosophy, Chicago, 1982, contiene los textos de las lecciones sobre la filosofía de Kant y de un seminario sobre la Crítica del Juicio, realizados en la New School for Social Research de New York en el otoño de 1970. Ellas constituyen el material del cual la autora habría elaborado la Tercera Parte de The Life of the Mind, "Judging" y que no alcanzó a terminar porque fue sorprendida por la muerte en diciembre de 1975.
} 
na por la cual nos insertamos en un mundo donde ya están presentes los otros.

En este contexto, su concepción de la política es teatral. Los actores necesitan trabajar para mantenerse y un escenario sobre el cual actuar: dado el marco, la actuación es esencialmente pública y reveladora, pero, además, impredecible... En la labor, la humanidad se une como "especie"; en el trabajo, los agentes humanos tienen una relación aislada con la naturaleza; pero en la acción ${ }^{3}$, según Arendt, tenemos "hombres en plural", gente que actúa para $y$ con otros. La acción es la forma política de la actividad humana que tiene lugar dentro del espacio libre y abierto de un reino público construido y compartido. La política no es una cuestión de logro de fines; es una actividad continua de comienzos y nuevos comienzos sobre los que ningún actor puede ejercer un control absoluto. En la actuación, el actor se revela a sí mismo entre otros, muestra quién es, pero nunca con un completo conocimiento acerca de cuáles podrían llegar a ser las consecuencias de esto. Mientras la labor no tiene comienzo ni fin y el trabajo tiene tanto comienzo como fin, en la acción hay comienzo pero el actor no puede conocer el final.

De este modo, lo imprevisto hace constante acto de presencia en la esfera de los asuntos humanos, en razón de la autoapertura espontánea que caracteriza a la acción en el terreno de lo público y a su capacidad para poner en movimiento más de lo que el agente puede prever: "Aparecer siempre implica parecerle algo a los otros, y ello siempre varía en función del punto de vista y la perspectiva de los espectadores (...) El "parecer" algo se corresponde con el hecho de que cada apariencia, a pesar de su propia identidad, es percibida por una pluralidad de espectadores"(LM, 34) ${ }^{4}$.

\footnotetext{
${ }^{3}$ Para una mayor profundización de estas categorías, ver los capítulos III. IV y V de La condición humana.

+ Refiriéndose al acontecimiento que siempre tiene lugar en el espacio de lo público escribe en otro lugar: "Es más, los hechos y los acontecimientos - el resultado invariable de los seres humanos viviendo y actuando juntos- son la auténtica textura de la esfera politica", en "The Modern Concept
} 
El espacio de aparición cobra existencia siempre que los hombres se agrupan por la acción, la cual sólo es política si va acompañada de la palabra (lexis). Y ello porque, en la medida en que siempre percibimos el mundo desde la distinta posición que ocupamos en él, sólo podemos experimentarlo como mundo común en el habla. Sólo hablando es posible comprender, desde todas las posiciones, cómo es realmente el mundo: "El poder -dice Arendt- sólo es realidad donde palabra y acto no se han separado, donde las palabras no están vacías y los hechos no son brutales, donde las palabras no se emplean para velar intenciones sino para descubrir realidades, y los actos no se usan para destruir sino para establecer relaciones $y$ crear nuevas realidades" $(\mathrm{CH}, 230)^{5}$.

\section{b. Kant: estética y política desde la perspectiva de Arendt.}

En los orígenes del totalitarismo y la condición humana arendt no se basa explícitamente en la obra de kant. de hecho, en el último texto, su filosofía política se desecha sumariamente como la culminación de una corriente moderna que considera a la actividad política como primariamente legislativa ${ }^{6}$.

De todos modos, las concepciones de Arendt acerca de la verdad y la moralidad regidas por la ley, así como las diferencias rígidas que marca entre teoría y práctica, y entre lo animal y lo distintivamente humano, reflejan la influencia de Kant sobre su pen-

of History", en The Review' of Politics, 1958, pp. 570-590, reeditado en Between Past and Future con el título de "The Concept of History: Ancient and Modern". (Trad. propia)

"Arendt vive en "tiempos de oscuridad" las tensiones generadas por el proceso de industrialización provoca la disolución de la estructura racional de la historia y el imperio de la ley, con la consiguiente dispersión de los discursos políticos y el sordo avance de la fuerza. Una época tocaba a su fin y, con ello, los actos de una ciega violencia irracional minaban los cimientos del Estado de derecho. Ver: Arendt, H., Men in Dark Times, New York, Harcourt, Brace and Wolrd, 1968, (Trad.Esp.: Hombres en tiempos de oscuridad, Barcelona, Gedisa, 1990); y, Arendt, H., The Origins of Totalitarịanism. New York, Meridiam Books, The World Publishing Company, 7a. ed., sept., 1962 (Trad. Esp.: Los origenes del totalitarismo, Madrid, Taurus, 1974). En adelante OT.

${ }^{6}$ Ver ARENDT,H., La condición....,pp. 174-176. 
samiento. Más específicamente, la distinción entre los tres modos de vita activa reproducen aquella que Kant estableciera entre las tres disposiciones humanas: "animalidad", "humanidad" y "personalidad" al contrastar el impulso por la satisfacción física, la satisfacción por el logro de fines dictados por el deseo y la predisposición a la autolegislación ${ }^{7}$.

No obstante, el elemento kantiano más significativo en la exposición que desarrolla Arendt de la condición humana, se reconoce en su caracterización de "lo político" como un reino de pura espontaneidad que puede adquirir significado por medio del “...sentido común que nos permite juzgar como espectadores"(LM, 526). Esta noción de vida política que Arendt pretende recuperar de un Kant excesivamente identificado con las constricciones homologantes y unificantes de la "ratio", será desarrollada principalmente, a partir de la noción kantiana de "juicio reflexivo" y de su capacidad para mediar entre la vita activa y la vita contemplativa, o, en términos kantianos, entre lo "empírico" y lo "trascendental".

La importancia del juicio para el pensamiento político de Arendt se señala ya en La condición humana en el rol del historiador y del narrador, pero esta importancia no se manifiesta hasta que queda clara en las disertaciones expuestas en La vida del espíritu en las que presenta al juicio como la facultad mental que relaciona la vida de la mente con la vida del mundo. La posición de Arendt sobre el juicio se sustenta explícitamente en el planteo de Kant sobre el "juicio reflexivo" conforme lo expone en la tercera crítica ${ }^{8}$.

\footnotetext{
${ }^{7}$ Este paralelo podría ser profundizado en el sentido de que aún cuando Arendt no hace al respecto una referencia explícita a Kant, las suposiciones con las que trabaja son fundamentalmente kantianas. Ver KANT, E., La religión dentro de los limites de la mera razón, trad. cast. de F. Martínez Marzoa, Madrid, 1981 y ARENDT, H., La condición humana, op. cit., capítulos III, IV y V.

${ }^{8}$ La Critica de la Facultad de Juzgar ( Kritik der Urteilskraft) designada en adelante con la abreviatura KUK, se publicó por primera vez en 1790. Hubo otras dos ediciones (1793 y 1799) en vida de Kant. Se cita parágrafo de la obra de Kant, con volumen y página de la edición de Wilhelm Weischedel publicada por Suhrkamp Verlag en 1977. Confrontamos con las versiones españolas de Manuel García Morente, Madrid: Espasa-Calpe, 1981, y de Pablo Oyarzún, Caracas, Monte Avila, 1991. Siguiendo una costumbre ya establecida por la traducción de García Morente, "Juicio" corresponde a Urteilskraft, la capacidad de juzgar, mientras que "juicio" es Urteil, el enunciado que
} 
Para Arendt, la Crítica del Juicio -y su "Analítica de lo bello"-, es la que mejor se presta a la empresa de "rehabilitación ontológica" del "singular". Kant reconocería en la competencia de una "facultad subjetiva" la posibilidad de un contacto directo con los fenómenos sustrayéndolos al marco de la determinación conceptual: " $\mathrm{La}$ mayor dificultad en el juicio -dice Arendt- radica en que es la facultad de pensar lo particular'; pero pensar significa generalizar, por lo tanto es la facultad de combinar misteriosamente lo particular y lo general"'(LM, 534).

Los pasajes claves de la Crítica del Juicio que sirven a la autora para destacar este paradojal arte de "pensar" el "singular", son aquellos en los que se señala la capacidad discriminatoria del "gusto" a la vez que su universal potencialidad de operar como "sensus communis" en un marco conceptual diferente, el de las noción de "imaginación" y de la distinción entre la validez universal (Allgmeingültigkeit) objetiva y subjetiva". Para Kant, el “juicio reflexivo" estético, posee una subjektive Allgemeingültigkeit (una validez universal subjetiva) por oposición a la validez universal objetiva de los juicios formulados, por ejemplo, en el campo teórico. Ese juicio "reflectante" se refiere al gusto y depende de la posibilidad que el sujeto tiene de colocarse "en el lugar de otro". Ninguna condición de esta naturaleza se requiere en los casos de juicios de validez universal objetiva en los que el "otro" (desde el punto de vista del quid juris) no presenta el menor interés. En otras palabras, en las cuestiones teóricas no tengo que preocuparme de esto, puedo prescindir del asentimiento de los "demás" y ya no tengo necesidad de observar las cosas desde "el punto de vista de los otros"10.

\footnotetext{
Urteilskraft, la capacidad de juzgar, mientras que "juicio" es Urteil, el enunciado que juzga.

"Para Arendt, Kant utiliza las palabras latinas para indicar que se refiere a algo distinto: a un sentido adicional que nos integra en una comunidad: "El sensus communis es el sentido especificamente humano, porque de él depende la comunicación. el lenguaje..." (LM. 531).

${ }^{1 "}$ La "validez universal objetiva", tal como la concibe Kant, equivale prácticamente a un aislamiento perfecto de la "conciencia teórica" y por consiguiente a una forma de solipsismo. Por ejemplo, Kant hace total abstracción de la inseparabilidad del pensamiento y del lenguaje como problema teórico (y
} 
A diferencia del "ojo de la mente" del "Yo Pienso", que sólo en el aislamiento puede percibir la verdad del ser, en el texto kantiano del cual Arendt se hace eco, la imaginación nos pone en una virtual comunicación con los otros: "La universal comunicabilidad subjetiva del modo de representación en un juicio de gusto, debiendo realizarse sin presuponer un concepto, no puede ser otra cosa más que el estado de espíritu en el libre juego de la imaginación y del entendimiento (en la medida en que éstos concuerdan recíprocamente, como ello es necesario para un conocimiento en general); en cuanto somos conscientes que esta relación subjetiva, propia de todo conocimiento, debe tener igual valor para cada hombre y, consiguientemente, ser universalmente comunicable..." (KUK, §9, X, 29). De este modo, Arendt funda su tesis de la naturaleza "esencialmente política del juicio" en su interpretación del rol que Kant le hace jugar a la noción de "sensus communis. El "sentido común" sería aquella cualidad que constituye a los hombres en partícipes de una comunidad, no ya por la convergencia en la necesidad apodíctica de un juicio cognitivo, sino por justificar el asentamiento en una universalidad condicionada por las reglas del gusto. "Si los juicios del gusto (al igual que los juicios de conocimiento) tuviesen un principio objetivo determinado, quien los emitiese de acuerdo a éste pretendería que su juicio tuviese necesidad incondicionada. Si careciera de todo principio como los del mero

no psicológico). Al mismo tiempo afirma (en la Crítica del Juicio), bastante curiosamente, desde el punto de vista "trascendental", que no hay conocimiento sin comunicación. Por su parte, el "gusto", el "sentimiento", la intuición de lo "bello", ocupan a los ojos de Kant una posición particular en este contexto, puesto que ellos revelan una insuperable singularidad lógica, que sólo es comprensible reflexivamente, sobre el fondo de una espontaneidad particular; en ninguna otra parte la tensión entre el "caso" y la "regla", entre "lo particular" y "lo general", se ha elevado al rango de apuesta filosófica de manera tan radical. Entre los campos donde la razón es puesta a prucba por lo "singular" -lo bello, el arte , y pronto, la historicidad- sólo los fenómenos "estéticos" exigen que se comprenda al sujeto como un agente radicalmente reflexivo que encuentra el principio determinante de su juicio únicamente en una "regla" no dada. Lo que llamamos a menudo "formalismo" del gusto toma su origen en esta tensión insuperable entre lo particular y lo universal, donde el sujeto no es propiamente legislante, y si legisla lo hace por su propio "sentimiento". Que el sentimiento deba siempre, según Kant, ser mediatizado por un juicio (el juicio del gusto), que basa su reivindicación de universalidad (y de comunicabilidad) sobre el mantenimiento de una estructura cognitiva potencialmente universalizable del sujeto estético, testimonia la inserción de la especificidad de la estética kantiana en un ámbito más amplio: aquel del carácter a priori de la subjetividad. 
gusto de los sentidos, no se llegaría a concebir siquiera [que tuviesen] necesidad alguna. Deben tener por consiguiente, un principio subjetivo que determine, sólo por sentimiento y no por concepto, y sin embargo, con validez universal, lo que le plazca o displazca. Pero un tal principio sólo podría ser considerado como un sentido común, que es esencialmente diferente del entendimiento común, al que hasta ahora se llama también sentido común (sensus communis); este último,en efecto, no juzga según sentimiento, sino siempre según conceptos, si bien comúnmente, sólo como principios oscuramente representados" (KUK, §20,X, 157).

Sirva esta extensa transcripción del texto de Kant para analizar la interpretación que realiza Arendt de la noción de sensus communis, en el contexto de su propia concepción de "lo político". El sensus communis del cual habla Arentd puede hacerse coincidir con una suerte de "a priori factual" que, sin pretender definir la naturaleza humana, tiene, sin embargo, la función de circunscribir una diferencia específica: aquella que distingue al hombre del animal. El sensus communis no coincide con un principio ontológico que funda la natural sociabilidad del hombre y, por ende, la existencia de la comunidad política, pero es un dato de hecho fenomenológicamente incontrastrable que se presenta al mismo tiempo como la condición de posibilidad del lenguaje, de la comunicación y del compartir en general: es la pluralidad de los individuos que constituyen una comunidad $-\mathrm{y}$ sus diferencias-, precisamente porque nos pone ante el hecho de la diversidad de los juicios de los otros, la necesidad de su reconocimiento y la posibilidad de trascender el coto cerrado de la propia singularidad.

El juicio, según es comprendido por Arendt, rescata a la acción de la pura arbitrariedad y a la filosofía de su irrelevancia para la acción. Mientras que en La condición humana el filósofo parece correr el riesgo de desaparecer completamente de la polis, en la filosofía política del juicio se celebra el rol del espectador en la medida en que el juicio es un proceso mental que incluye la habili- 
dad de pensar desde el punto de vista de los otros y, en consecuencia, remite a una "mentalidad ampliada" que puede extenderse hasta abarcar a toda la humanidad: "...Es en virtud de esta idea de humanidad, presente en todo ser humano, por lo que los hombres son humanos y pueden considerarse civilizados o humanitarios hasta el punto que esta idea se convierte en el principio de sus acciones así como en el de sus juicios(...)El, por decirlo así, imperativo categórico para la acción podría leerse así: Actúa siempre según la máxima a través de la cual este pacto originario puede ser actualizado en una ley general"(LM, 534). Este ideal, según Arendt, se halla implícito en la referencia de Kant a un contrato original dictado por nuestra mera humanidad en la Crítica del Juicio, referencia hecha en el contexto de una discusión sobre el interés humano empírico en la comunicabilidad de la belleza "...sentimiento universalmente comunicable $y$, por cierto, sin mediación de los conceptos."(KUK, §39, X, 224).

Para Arendt, el mundo común de los seres humanos, al que la facultad de juzgar apela, resulta no ser una totalidad ética existente, sino una idea regulativa, a saber, el sensus communis que demuestra sobre todo su realidad en esos raros momentos en el que el juicio autónomo rompe la costra de las opiniones y prejuicios establecidos. Aquí Arendt recuerda las tres máximas de este "común entendimiento humano" conforme lo establece Kant en el $\S 40$ : "pensar por sí mismo(la máxima de la Ilustración); pensar en el lugar de cada uno de los otros la máxima de la mentalidad extansiva), y la máxima de la consecuencia (pensar siempre de acuerdo consigo mismo, mit sich selbst einstimmig denken)" (LM, 532).

De este modo, en el concepto de Kant sobre el juicio reflexivo, la facultad humana que es legal sin ley, Arendt considera haber encontrado lo que estaba buscando, una filosofia politica que no es una filosofía del derecho. Intrínsecamente relacionado con la esencial pluralidad de los seres humanos, el juicio conforme se plantea en la Tercera Crítica, queda explícitamente relacionado a la 
idea de un acuerdo intersubjetivo sin la obligatoriedad para todo ser racional que caracteriza al juicio moral: "El juicio no es razón práctica; la razón práctica 'razona'y me dice qué hacer y qué no hacer; establece la norma y es idéntica a la voluntad, y ésta expresa mandatos, habla en imperativos. En el juicio, la 'extensión del espiritu' juega un papel fundamental. Esta se consigue 'comparando nuestro juicio con el juicio posible más que con el juicio real de los otros, y colocándonos en el lugar de cualquier otra persona'. La facultad que hace esto posible se llama imaginación(...) Mediante la imaginación el pensamiento hace presentes a los otros y se mueve así potencialmente en un espacio que es público, abierto a todas las partes, adopta la posición del ciudadano del mundo de Kant"'(LM, 518-519).

Es en Kant donde Arendt parece encontrar lo que necesita para su propia teoría del juicio. Sin embargo, pueden señalarse dos cuestiones que pondrían de manifiesto el carácter problemático de su concepción: la primera tiene que ver con la sustentabilidad y plausibilidad de su interpretación del concepto de Kant de "juicio reflexivo"; la otra, con las implicancias de la apropiación del texto kantiano para la filosofía política que intenta fundar.

La lectura que hace Arendt de la filosofía política de Kant se distingue en particular por su renuncia a reconocer cualquier relación entre el proyecto de las primeras dos críticas, limitadas a legislar para el reino de la razón teórica y práctica, respectivamente, y el proyecto de la crítica del juicio estético del gusto y de los escritos sobre la Ilustración y la historia. Avanzando en esta línea, reconoce en la concepción kantiana del gusto una solución al problema de la "singularidad" en el preciso lugar en el que para el propio Kant se compromete la autoridad legitima a priori de un consentimiento universal localizado subjetivamente en el sentido del placer. La "estética filosófica", que se constituye en esta época como discurso filosófico específico, toma por objeto esencialmente al "sujeto estético" receptor y productor con sus distintos princi- 
pios. Esta "autonomía" estética se manifiesta en una actividad subjetiva específica, irreductible por naturaleza a las otras disposiciones subjetivas como el conocimiento o la moral, pero ella no constituye por esto una dimensión independiente de las otras disposiciones del sujeto. La "crítica de la facultad de juzgar" debe entonces ser devuelta a su espacio de inteligibilidad propia, aquel de la "estética de las Luces", mientras que se comprenda aquí a las "Luces" (o la Aufklärung), de manera kantiana, como un proceso de subjetivación por el cual el sujeto teórico, moral, religioso, político, estético, etc., se apropia nuevamente de los contenidos tradicionales para someterlos a las leyes a priori de la subjetividad.

Para Kant, según vimos, la autoridad del juicio del gusto se halla ligada al concepto de sensus communis. Queda claro que el sensus communis implica y es implicado por la comunidad y la sociabilidad humanas; sin embargo, no por esto se halla menos intrínsecamente articulado con las condiciones universales de la cognición y de la moralidad. Aún cuando Kant se refiere al juicio estético, lo que dice indica que el pensar desde un punto de vista universal está íntimamente conectado con la distinción entre materia y forma. El elemento formal representa lo que no es meramente subjetivo y lo que, por consiguiente, pertenece a un punto de vista universal: "Por sensus communis hay que entender, no obstante, la idea de un sentido que es común a todos, esto es, de una facultad de juzgar que en su reflexión tiene en cuenta por pensamiento (a priori), el modo de representación de cada uno de los demás , para atener su juicio, por así decirlo, a la razón total humana y, así, evitar la ilusión que, nacida de condiciones privadas subjetivas, tendría una influencia perjudicial en el juicio" (KUK, §40, X, 225). No hay duda de que Kant piensa aquí en el acuerdo entre "la libertad de la imaginación con la legalidad del entendimiento". Es a la facultad de juzgar que le corresponde la tarea de mostrar esta armonía in concreto, no reposando en una determinación conceptual objetiva, pero tampoco en principios meramente "empíricos". 
Lo expuesto conduce al reconocimiento de dos aspectos que parecen no ser contemplados por la lectura de Arendt:

1) el juicio estético está en Kant, indisociablemente ligado a la evolución de la comunidad humana: "Fue con propósito benévolo que aquellos que de buen grado querian dirigir todas las ocupaciones de los hombres, a las cuales impulsa a éstos la disposición natural interna, hacia el fin último de la humanidad, a saber, el bien moral, tuvieron por signo de un buen carácter moral el tomar, en general, interés en lo bello" (KUK, §42, X, 231).

2) Su versión del juicio está fundada en las condiciones trascendentales del juicio en general y ligada a los fundamentos suprasensibles de la razón teórica y práctica: "Pues si también en esta forma debiera develarse un interés a él vinculado, vendría el gusto a descubrir un tránsito de nuestro juicio del goce sensible al sentimiento moral; y no sólo porque a través de ello nos veríamos llevados a ocupar mejor el gusto, en conformidad a fin, sino que también éste vendría a ser representado como el eslabón medio de la cadena de las facultades humanas a priori, de la que tiene que depender toda legislación" (KUK, §41, X, 230).

De este modo, Arendt pasa por alto sin resolver en el terreno estético lo que tarde o temprano reaparece en el campo de su teoría política: la tensión entre el sensus communis y la trascendentalidad del juicio que caracteriza al pensamiento de Kant; omisión que reaparece en su propia versión del juicio político cuando debe dar cuenta de la articulación entre los momentos empíricos y trascendentales del "pacto originario de la humanidad"(LM, 534). Si tenemos presente que el punto de partida de la filosofía política de Kant es la división entre moralidad y legalidad, pero además, que el rol que éste le hace jugar al principio puro del derecho es nada menos que el de asegurar externamente la obediencia al imperativo categórico que es internamente garantizado por la virtud: es muy difícil desfundar el juicio de toda legitimación trascendental y, a la 
vez, como pretende Arendt, considerar que es posible seguir defendiendo su legitimidad.

En otras palabras, debido a que Arendt desecha la filosofía del derecho de Kant, adopta la división actor/espectador que le ofrece la versión kantiana sobre el juicio reflexivo sin localizar los orígenes de esa distinción en el contexto amplio del pensamiento político de Kant. Para Arendt la prioridad del espectador sobre el actor es una consecuencia necesaria de la pertenencia del espectador a la "mentalidad ampliada" que caracteriza al juicio; mientras que para Kant, hay algo que es "previo" a la actitud contemplativa del ciudadano como "espectador": éste se halla gobernado por las prescripciones del derecho, al punto que el sentido último de su juicio le viene dado por su referencia e indisociable vinculación a la idea del progreso hacia el ideal indeterminado de la comunidad jurídica perfecta.

El resultado de la apropiación que Arendt hace de las concepciones kantianas del juicio, se orienta en orden a justificar la reconciliación simple y directa entre vita contemplativa y vita acti$v a$, mientras que en realidad en Kant, la autoridad del juicio se encuentra ambivalentemente localizada en la comunidad empírica y la legislación trascendental, ambivalencia que representa para Kant, nada menos que aquella tensión necesaria y no conmensurable entre el reino de la acción y el reino del pensamiento.

De este modo, para Arendt, la filosofía política genuina queda identificada con el juicio kantiano desinteresado del gusto, el cual, sobre la base del sensus communis, permite la discriminación en la evaluación de la vida política y el progreso en la historia. Esta identificación confiere originalidad al juicio arendtiano. Sin embargo, como veíamos más atrás, al tratar de justificar la capacidad para tal juicio, Arendt pasa por alto el doble aspecto que caracteriza al sensus communis como una capacidad empírica y como situada en el campo trascendental, conforme se presenta en el pen- 
samiento de Kant. Esto lleva a una ambigüedad inevitable en cuanto a la justificación de su propia práctica filosófica: por una parte, la filosofía política es una contribución al diálogo político que se sitúa en el reino de la acción, y, por otra, Arendt le confiere la capacidad para operar como criterio para determinar acerca de lo que se considera o no como "acción" en el reino político: "Es en este punto donde actor y espectador se llegan a unir; la máxima del actor y la máxima, la 'pauta', a partir de la cual juzga el espectador el espectáculo del mundo se convierten en una"(LM, 534).

El objetivo de Arendt se cierra cada vez más sobre la preocupación por liberar tanto a la práctica como a la comprensión de la política de las restricciones de la ley, la verdad y la moralidad. Desde su perspectiva, el interés por la ley y las cuestiones sobre el orden y el gobierno, han desviado la atención de la capacidad distintivamente humana de la acción a la que ella propone volver. El resultado ha sido, la intromisión de los intereses privados en el reino de lo público y la reducción del poder a la violencia. Por otra parte, la preocupación por la verdad y la moralidad ha estimulado la subordinación de la política a fines supuestamente superiores, lo que conduce a la destitución del valor intrínseco de la acción política. El juicio representa un camino osado para la política y para la filosofía política que, en principio, es antitético tanto en lo que respecta a las condiciones que hacen posible el totalitarismo como al punto de vista del filósofo. "El espacio de la aparición cobra existencia siempre que los hombres se reúnen en el espacio de la palabra; precede en consecuencia a toda constitución formal del dominio público. En cualquier lugar donde se reúnen hombres, allí se encuentra en potencia, pero solamente en potencia, no necesariamente ni para siempre". (CH-263)

La necesidad del discurso en comparación con otras realizaciones humanas en las que éste es únicamente medio de comunicación, se constituye en uno de los aspectos más destacables de la acción. Es mediante la acción y el discurso como aparecen los 
hombres en un mundo humano y como revelan activamente su única y personal identidad. Paradójicamente, si bien para la Arendt, la vita contemplativa es un quehacer solitario, no político, reafirma su autoridad en el terreno práctico cuando se trata de realizar una reapropiación selectiva del pasado y de iluminar críticamente el presente. Este sentido de "iluminación" va a tener una plasmación muy concreta en el juicio histórico. A pesar de la carga agustiniana del término, adquiere en Arendt un sentido totalmente distinto al situarse en el esquema kantiano de la crítica de la facultad de juzgar: desde su interpretación del juicio estético de Kant, formula su concepción del juicio político e histórico a partir de una noción del "sujeto" como "espectador" que trata de comprender el significado de los asuntos humanos en su particularidad y en su "validez ejemplar".

\section{c. Diversas lecturas del texto arendtiano.}

Hay un tipo de receptividad reservada a las elaboraciones sobre el juicio kantiano conducidas por Hanna Arendt -en particular, en las Lectures on Kant's Political Philosophy- para hacer de la Urteilskraft (juicio estético) y del "sensus communis", los paradigmas de un nuevo, o "neo-antiguo", proyecto de integración más o menos armónica entre sujeto y comunidad política.

Se ha pensado que, desde la obra de Arendt, podría elaborarse una "teoría del juicio político", para poder delinear una sistemática y completa "teoría filosófica de lo político" que, al retener la carga innovadora de la autora, cumpla el doble cometido de constituir un verdadero y explícito cambio de paradigma, al tiempo que se diferencia de aquellos otros proyectos que se limitan a reproponer una inactual "phronesis". En esta línea puede reconocerse a Ronald Beiner, quien en su libro Political Judgement ${ }^{11}$ quiere derivar del pensamiento de Arendt, una teoría centrada sobre una

\footnotetext{
${ }^{11}$ Beiner, R., Political Judgment, London, Methuen, 1983.
} 
fuerte noción de "ciudadanía". Para el comunitarismo" de Biener, el problema no es colocar la orientación intersubjetiva sobre un plano racional y universal, sino ubicar la posibilidad de consenso en el tejido concreto y vital de una comunidad, en la trama viviente de un "ethos" compartido. El juicio, tal como es interpretado por Arendt, considera a los sujetos capaces de orientarse en los contextos particulares en los cuales no rigen normas universales, otorgándoles un espacio de deliberación y de participación en la vida pública sin instancias previas a las creadas por la palabra de los propios actores. Pero si la Arendt ha tenido el gran mérito de haber llamado la atención sobre la más política de las facultades humanas, la facultad de juzgar, tanto el juicio como la continua noción de "sensus communis", no se presentan para Beiner lo suficientemente adecuados para diseñar la dinámica concreta sobre la cual una comunidad puede ser construida. En síntesis, según este autor, Hanna Arendt debería haberse conservado más cerca de Aristóteles y su doctrina de la "phronesis", la cual nos sugiere más en concreto cómo orientarnos en orden al "buen vivir", antes que detenerse en la abstracta perspectiva kantiana. En última instancia, Beiner se define, no obstante las innumerables afirmaciones de estricta observancia arendtiana, mucho más cerca de Gadamer $^{13}$ para fundar su propio proyecto teórico.

\footnotetext{
${ }^{12}$ Cabe señalar que el comunitarismo no es un movimiento de pensamiento unitario y homogéneo, sino más bien convergente en un mismo objetivo polémico: la racionalización moderna tal cual es resuelta en el campo de la teoría ética, política y critica del liberalismo. En grandes líneas, se puede observar que el pensamiento de los "communitarians" se dispersa en dos direcciones: la primera -que se identifica por ejemplo en los trabajos de Mac Intyre y Sandel- "integracionista" por así llamarla, está preocupada en resolver los problemas del individualismo y de la anomia modernas, orientándose casi "tout court" a la recuperación de los valores tradicionales como los religiosos; la segunda, "participacionalista", más atenta a soluciones de tipo político e institucional lamenta no sólo y no tanto la pérdida moderna de unidad, solidaridad y permanencia, sino sobre todo la reducción del espacio para una auténtica acción política. A esta segunda perspectiva, que presenta mayor consonancia con el pensamiento arendtiano, pueden ser referidas las posiciones de Walzer y de Taylor, así como las del discípulo de este último, R. Beiner.

${ }^{13}$ Gadamer, H. G., Verdad y método, Salamanca, Sígueme, 1977: particularmente en sus nociones de "sensus comunis" y de "juicio".
} 
Por su parte, el programa filosófico de la ética del discurso -al menos en algunos de sus representantes-, parece orientado a integrar la perspectiva abierta por las Lectures. El mismo Habermas ha reconocido cuánto le debe su propia teoría de la interacción comunicativa, a la obra desarrollada por $\mathrm{H}$. Arendt al punto de reconocer en sus estudios, “... un primer paso hacia una noción de racionalidad comunicativa que se basa sobre la acción y sobre el discurso". Sin embargo, quien más se preocupa por intentar un acuerdo entre la perspectiva arendtiana y la de la ética discursiva es Sheyla Benhabib", quien se vuelve al "judging" arendtiano para buscar allí el modelo de una posible acción moral, entendida como "interacción comunicativa". Especialmente, en el marco de las "Lectures...", Benhabib individualiza el lugar de un posible diálogo entre "teoría de la acción comunicativa" y "comunitarismo": al despojar a la concepción kantiana de los aspectos excesivamente abstractos y formales articulándola de manera original con la "phronesis" aristotélica, H. Arendt habría abierto la vía para una mediación entre la actitud particularista hacia el contexto y un punto de vista moral universalista ${ }^{15}$.

Pero no solamente en el contexto de un pensamiento enmarcado en la línea de la teoría crítica -anglosajona o continental-, pueden reconocerse análisis importantes de la obra de Arendt. J. F. Lyotard, se ha detenido muy especialmente, en la interpretación que la autora realiza -de manera "indebida" según él- de la Crítica del Juicio de Kant ${ }^{16}$.

\footnotetext{
${ }^{14}$ Sheila Benhabib -asi como otros dos autores importantes de EE.UU: R. Bernstein y T. McCarthydebe gran parte de sus propias premisas a la "pragmática universal" de Habermas, tratando de mediar entre presupuestos de la ética del discurso con perspectivas politicas que provienen del universalismo del pensador alemán. Relevantes, en este contexto son los ensayos: "Autonomy, Modernity and Comunity. Comunitarianism and Critical Social Theory in Dialogue" in A. Honneth, S. Mulhall, A. Swift (ed.) Liberals and Comunitarians, Cambridge, Mass, 1992; "Judgement and the Moral Fondations of Politics in Arendt's Thought Political Theory, XVI, n. 1, 1988, pp. 29-52. Siendo la obra con que se ganó el reconocimiento del mundo anglosajón: BENHABIB, S., Critique, Norm and Utopia. A study of the of Foundations of Critical Theory, New York, Columbia University Press, 1986.

${ }^{15}$ Benhabib, S., "Judgement and the Moral Fondations...", cit. p. 50.

${ }^{16}$ Lyotard,J.F., "Survivant", Lectures d'enfance, Paris, 1991, pp. 59-87.
} 
Lyotard le cuestiona el haber sacrificado la validez trascendental del juicio del gusto y del "sensus communis", para transformar estas nociones en las categorías convalidantes de un proyecto político radical: aquél de una comunidad todavía prisionera de las premisas de la autogestión moderna hechas valer por Hegel. En otros términos, no discute el contenido y la pertinencia de la propuesta, sino la proyectualidad, como tal, de una comunidad política que a su parecer -puede leerse entre líneas en las "Lectures..." de Arendt-, es el signo de un pensamiento todavía demasiado "reconstructivo", el cual, a pesar de los esfuerzos por distanciarse de la lógica dialéctica, no logra al final sino ir a desembocar en la contradicción, y, por ende, en la consiguiente reconciliación de sujeto y objetividad política. En síntesis, para Lyotard, la reflexión arendtiana permanece deudora de las exigencias de la autocompresión hegeliana que le quita a la filosofía la posibilidad de configurarse en un "lugar de resistencia".

De este modo, mientras, $\mathrm{H}$. Arendt parece desilusionar las expectativas de todos aquellos que buscan en su teoría del juicio la categoría práctica que les permita legitimar la dimensión éticopolítica de una comunidad empírica, otros le imputan, desde posiciones opuestas, el haber dado vida a una suerte de "mitología" del juicio, expresión de una concepción no desarrollada e incluso metafísica. En tanto, los habermasianos le cuestionan el no seguir hasta el final las implicaciones del "racionalismo crítico intersubjetivo" de Kant, los "communitarians" vislumbran en la utilización de la sola perspectiva trascendental kantiana -no unida adecuadamente a la de "phronesis" aristotélica-, el carácter excesivamente abstracto de un juicio que permanece políticamente ineficaz. Si por un lado, los partidarios de la ética discursiva aplauden la identificación arendtiana del "sensus communis" con una idea regulativa para una práctica discursiva lo más amplia posible, por otro, los comunitaristas se lamentan exactamente de eso. Están dispuestos a seguir el discurso arendtiano sobre el juicio sólo hasta donde éste parece acercarse a la "phronesis" aristotélica y abandonarlo cuando la ape- 
lación a Kant impide que la noción de "sensus communis" pueda ofrecer sostén al funcionamiento de una comunidad que se expresa y se renueva sobre la base de un "ethos" compartido.

\section{d. Consideraciones finales.}

Según Hanna Arendt, la capacidad para juzgar es una habilidad específicamente política. El énfasis en la comunicación, la imaginación y la representación de las opiniones de los otros en un espacio público, nos permite entender la manera en que el juicio interviene en la configuración del propio punto de vista. En este contexto, la formación de opiniones asume un protagonismo tan central como posibilitante del horizonte político, el cual se constituye sobre la base de la articulación dinámica de tres factores fundamentales: la pluralidad como condición básica de una comunidad de iguales, la imaginación para representar las otras perspectivas y la valentía para someterlas públicamente a la consideración de todos.

Arendt encuentra en la Primera Parte de la Crítica de la Facultad de Juzgar, la filosofía política "no escrita" de Kant. Es en el dominio del juicio estético donde para Kant los demás deben ser tomados en consideración como otros; el otro no difiere de mí "numéricamente" sino sustantivamente. A pesar de las connotaciones del término "reflexivo", en este tipo de juicio, el otro no es un "espejo"; más aún, puede cumplir el lugar que Kant le asigna porque es otro (diferente en un sentido no superficial). Esto implica discriminar y discernir lo particular en su particularidad, a la vez que requiere de una "mentalidad ampliada" (eine erweiterte Denkungsart) gracias a la cual somos capaces de pensar en el lugar de todos los demás. De este modo, el juicio basado en el gusto no implica identificar a este último con los "sentimientos privados"; al contrario, el gusto es una especie de "sensus communis", desde el cual, el juicio adquiere una "validez universal subjetiva" alejada del tipo de universalidad propia de la razón teórica, donde se configura 
como identidad de las ejemplificaciones numéricas indefinidas e indiferentes. Ni la expresión de los sentimientos privados, ni el producto solipsista del diálogo del pensamiento consigo mismo; el poder del juicio adquiere validez en el dominio público por la presencia de otros "en cuyo lugar" se tiene que pensar.

Dado que para Hanna Arendt, la política debe entenderse en la línea de la actuación plural de los seres humanos en un espacio público definido -de tal modo que no se subsuma la acción particular en reglas universalmente determinantes-, la crítica del juicio estético de Kant, parece ofrecer las mejores posibilidades para redefinir radicalmente la relación entre filosofía y política. En lugar de que los filósofos se vuelvan hacia la política a fin de demarcar un espacio para el pensamiento y legitimar su filosofía política en la "inferioridad" de lo empírico, la vida de la mente es ahora la que adquiere relevancia política.

Atendiendo a cómo Arendt individualiza las modalidades temporales ocultas a la vida de la mente, resulta bastante clara la fisonomía del juicio. Si el pensar se sitúa en el eterno presente, y el querer está constitutivamente ligado al futuro, la dimensión temporal de la facultad de juzgar corresponde al pasado. Arendt alude expresamente al papel que desempeñaba la rememoración en Grecia, donde constituía una manera de dotar de cierta permanencia a las obras, hechos y palabras del ser humano, al punto que la rememoración, era la exigencia de los muertos a los sobrevivientes. Mnemosyne, la diosa de la memoria, es la madre de las otras musas, y, por eso: “... la memoria humana que narra la historia sobrevivirá al arrepentimiento así como a la destrucción.(LM,485).

Las reflexiones sobre "Judging" tienen, entonces, poco en común con el juicio implicado en la deliberación del "phroninos" aristotélico o en la dinámica intersubjetiva de la "ética de la comunicación", cuya dirección temporal está más bien orientada hacia el futuro. No parece que se pueda dudar de que las últimas reflexiones 
de Arendt sobre el juicio, como ella misma admite, coincidan en algún sentido, con una categoría de la comprensión histórica, aunque "sui generis" y, por lo tanto, representen un progresivo desplazamiento hacia los límites "externos" de lo político (algo así como un retorno -el cual no debe entenderse como "resolución"- a la noción de "contemplación" de la que en un primer momento parecía apartarse casi de manera definitiva) ${ }^{17}$. De ser así, esto implicaría leer su "judging" como el pasaje de un pensamiento que, a través de etapas bien distintas, reconduce al lugar del cual había querido tomar distancia: es decir, interpretarlo como si la misma Arendt hubiese sido finalmente "seducida" por aquella misma fuga del mundo de los actores humanos cuya puesta en cuestión se presentara, en un primer momento, como la razón de ser de su proyecto teórico. En otras palabras, como si su "giro" final fuese una "recaída" no consciente en la metafísica, a través de un juicio que, como ha sido más de una vez considerado, pertenece a la comunión de la mente consigo mismo en reflexión solitaria.

Está fuera de duda que en algunas obras precedentes a $L a$ vida de la mente, el juicio es considerado incluso bajo el perfil del actor, que actúa en consenso y que delibera sobre materias de interés común. Pero si se examinan atentamente las referencias a la opinión y a la "phronesis", en realidad se debe constatar que no resuelven la relación entre pensamiento y acción, mejor aún, no reconcilian teoría y práxis a través de la mediación del juicio político. En otras palabras, la facultad del juicio tal cual la concibe

\footnotetext{
${ }^{17}$ Casi todos los intérpretes arendtianos que han afrontado el tema del juicio han puesto de relieve la diferencia de consideración que subyace entre la primera y la segunda fase de su obra. Véase: M. A. Denneny, "The Privilege of ourselves: Hanna Arendt on Judging", en M. A. Hill (ed.), H. Arendt, The Recovery of the Public World, New York, 1979, pp. 245-276; D. Lories, "Sentir en commun et juger par soi-meme". Etudes Phénoménologiche, I, n. 2, 1985; R. Bernstein, "Qué es juzgar? El actor y el espectador" en Perfiles Filosóficos, México, Siglo XXI, 1991, pp. 253-272; F. Focher, "Sul giudizio politico", LI, 1986, pp. 13; A. M. Roviello, Sens commun et Modernité, Bruxelles, 1987; E. Young-Bruehl, "Reading Hanna Arendt's Life of the Mind", in Id., Mind and the Body Politic, New York-London, 1988, pp. 24-47. Además, el ya citado Political Judgement, de R. Beiner, en el cual el autor reconstruye integramente la temática del juicio arendtiano siguiéndola en todos los escritos de la autora.
} 
Arendt, no hace de nuevo de la acción la "consecuencia aplicada", la simple ejecución de un saber, aunque diferente del concebido por la tradición. De ser así, se re-propondría, por su parte, el carácter "derivativo" de la "praxis" que obedece a las orientaciones del pensamiento y retornaría al lugar del que había querido despedirse definitivamente. En este sentido, hay sobrados ejemplos de pasajes en su obra, especialmente en la parte final de la misma, donde más tenazmente y por propia coherencia, $\mathrm{H}$. Arendt lucha por resistir a la tentación de la "síntesis", de la "mediación" y de la "reconciliación".

Es verdad que la obra de Arendt comienza con la crítica de la separación entre pensamiento y acción que desde Platón lleva a subordinar la segunda a la primera, buscando constantemente desestabilizar el orden jerárquico conforme al cuál teoría y praxis se presentan en el interior de la filosofía política tradicional, para no sugerir ninguna respuesta acerca de cómo los términos pueden conectarse. Es cierto también que no nos lega una "nueva ciencia política" que ayude a hacer proyectos y a poner en orden el mundo de los actos humanos de un modo diferente al tradicional. Pero, todo eso, más que como una promesa incumplida o un desvío de los propósitos originarios, debe ser considerado como una salida inscripta en las premisas de este pensamiento crítico y radicalmente antisistemático, mucho más coherente de cuanto ella misma hubiera deseado admitir.

De este modo, Arendt no apela al legado de Kant para contribuir a respaldar una visión particular de la sociedad justa, más bien reconoce las ambigüedades radicales de los intentos kantianos por legitimar las pretensiones de la razón en la teoría y en la práctica. Su última palabra es así la identificación de una facultad subjetiva pero reflexiva; retrospectiva pero no simplemente descriptiva. Un juicio sobre el acaecer histórico, que si bien no se presta a mediar entre sujeto y objetividad política, o a diseñar los presupuestos de una ética discursiva, no renuncia, justamente por sustraer el ve- 
redicto final a la Weltgericht hegeliana, a reclamar al mismo tiempo la valencia ética de su autonomía en manos de quienes, sin el apoyo de reglas, convenciones y valores socialmente aceptados, o mejor aún, contra ellos, son todavía capaces de distinguir lo bueno de lo malo.

Concluyendo, la única autodescripción que Hanna Arendt aceptó como caracterización de lo que estaba haciendo fue la de ser una pensadora independiente. No pretendió escribir una filosofía política, ni transmitir una moral a fin de dar solución a los problemas humanos. Se resistió a toda especulación que tratara de resolver la brecha entre el pensamiento y la acción, al punto de considerar que existe una modalidad distinta de pensar que no se debe confundir con la cognición ni con la razón práctica: la capacidad de juzgar. Hacia el final de "Thinking and the Moral Considerations"(1971), escribe:"La manifestación del viento del pensamiento no es el conocimiento; es la habilidad del discernir el bien del mal, lo bello de lo feo. Lo que, tal vez, en los raros momentos en los cuales cada cosa está en juego, es realmente capaz de impedir las catástrofes."

\section{Resumen}

El núcleo central de este trabajo consiste en presentar a la Crítica de la Facultad de Juzgar de Kant como un recurso significativo en la formación del pensamiento político de Hanna Arendt. Según la interpretación que la autora realiza del juicio reflexivo y su vinculación con la comunidad ampliada presente en la concepción kantiana de sensus communis, es posible considerar una redefinición del juicio ahora más ligada a la contingencia de la acción y a la pluralidad de los espectadores en el ámbito de la esfera política. En síntesis, se trata de señalar los aspectos más problemáticos de la localización del legado de Kant en los últimos trabajos de Arendt a la vez que llamar la atención sobre la cuestión concerniente a la 
importancia del aporte kantiano a los ejes centrales del debate de la teoría política contemporánea.

\section{Abstract}

The core of this paper consists of presenting Kant's Critique of the Faculty of Judgment as a significant resource in the formation of Hanna Arendt's political thought. According to Arendt's interpretation of reflective judgment and its relation to the enlarged community that is present in the kantian conception of sensus communis, a redefinition of judgment, now closer to the contingency of action and the plurality of spectators in the realm of the political sphere is possible to consider. In short, the aim is to point out the most problematic aspects of tracing Kant's legacy in Arendt's latter works as well as to draw attention to the question concerning the importance of the kantian contribution to the key points of the discussion of contemporary political theory. 